\title{
Effect of diet and lifestyle on the bone mineral density of postmenopausal women of Mumbai
}

\author{
Samiya F. Z. Khan ${ }^{1, *}$, Fatima A. Kader ${ }^{2}$ \\ ${ }^{1}$ Research Dietician, ${ }^{2}$ Assistant Professor, ${ }^{1}$ Dept. of Medical Oncology, ${ }^{2}$ Dept. of Food Nutrition \& Dietetics, ${ }^{\mathbf{1}}$ Tata Memorial \\ Hospital, Mumbai, Maharashtra, ${ }^{2}$ College of Home Science, Nirmala Niketan, Mumbai, Maharashtra, India
}

*Corresponding Author:

Email: samiyakhan1508@yahoo.in

\begin{abstract}
Osteoporosis is a common public health problem affecting one in four women or one in eight men older than 50 years. The aim of the study was to categorize the percentage of women who are having normal BMD, osteoporosis and osteoporotic and to evaluate the relation between anthropometric profile, calcium intake (dietary and supplemental) and life style pattern with BMD. An observational study of 50 post-menopausal women was carried out using an interview schedule to collect information regarding diet, lifestyle and anthropometry. DEXA scan reports of the AP Lumbar spine (L1-L2), femoral neck left and femoral neck right sites were used to assess bone health. ANOVA and Pearson chi-square test were used and correlation was considered statistically significant at $\mathrm{p}<0.05$. The percentage of women with normal BMD, osteopenia and osteoporosis were $39.6 \%, 49.6 \%$ and $10.8 \%$ respectively. Higher percentage of Women with low BMI were osteoporotic. There was a significant positive correlation between BMD and frequency of intake of calcium rich foods (green gram dal, ragi, coconut dry, gingelly seed and milk) and a negative correlation of BMD with coffee intake. There was a positive correlation between the intake of calcium supplement and BMD of femoral neck left. In the present study it was observed that intake of calcium rich food and calcium supplement can have a positive effect on BMD of post-menopausal women. On the other hand lower BMI and coffee intake may have negative effects on BMD. Thus, dietary and life style patterns of post- menopausal women may significantly influence BMD.
\end{abstract}

Keywords: Post menopause, BMD (Bone mineral density), osteoporosis, osteopenia, DEXA Scan.

\section{Introduction}

The postmenopausal phase is a stage of experiencing permanent cessation of menstruation cycle over a year. It is now recognized as a time of decrease hormonal production with associated problems that reduce the quality and length of life for a large number of women. ${ }^{1}$ Bone loss accelerates substantially in the late peri menopause and continues at a similar pace in the first post-menopausal years. ${ }^{2}$ Loss of menses at any age is major determinant of osteoporosis with the menopause, either natural estrogen. Osteoporosis is characterized by low bone mass with micro architecture deterioration of bone tissue leading to enhanced bone fragility. This increases the susceptibility to fracture. Osteoporosis is a silent disease, discernible only in a low bone density, till a fracture occurs. Fractures in hip and spine are known to be the most important complication of the disease which leads to mortality and serious morbidity. Osteoporosis is a growing major common public health problem recognized in both developed and developing countries. ${ }^{3}$ By the year 2020 more than 700 million of the world population living above the age of 60 years will be from developing countries and 142 million will be from India .One in four women or one in eight men older than 50 years are believed to have osteoporosis. Studies on expatriate Indians, although on a limited number of subjects, have also shown a lower BMD as compared to that in Caucasians. This could reflect just differences, or may actually reflect poor bone health resulting from nutritional issues. There is a need to study the BMD fracture relationship in Indians to determine the ideal normative data for the Indian population. ${ }^{4}$ With increasing longevity of the Indian population, it is now being realized that as in the west, osteoporotic fractures are a major cause of morbidity \& mortality in the elderly. Conservative estimates suggest that of the population above 50 years of age, $20 \%$ of women \& about $10-15 \%$ of men would be osteoporotic. The total affected population would, therefore, be around 25 million. If the lower bone density is shown to confer a greater risk of fracture as is expected, the figure can increase to 50 million. ${ }^{5}$ Bone mineral density (BMD), bone quality and bone micro architecture determine the bone strength. There are some researches about related factors of osteoporosis and loss of Bone mineral density (BMD).They consist of advancing age, sex, smoking, menopause, low weight/weight loss, obesity, fat mass, low physical activity, alcohol consumption, calcium intake, muscle strength, family history of fracture/osteoporosis, and height/weight loss. ${ }^{6}$ Physical activity, optimal nutrition and adequate sun exposure are vital for attaining peak bone mass. Calcium and vitamin D nutrition plays an important role in determining bone health. A healthy lifestyle (diet, exercise and sunlight exposure) can have a major positive impact on the bone metabolism and bone health of Indian. ${ }^{7}$

\section{Material and Methods}

Present study was conducted in Mumbai at Kokilaben Dhirubhai Ambani Hospital and Medical 
Research Institute and was approved by the Independent ethics committee (ICE). Written consent was taken from patient before participation in the study. It was an observational study. 50 healthy post-menopausal women between the aged of 45 to 60 years were taken randomly as study subjects. Women who were below the age of 45 years or had a history of bone disease e.g. osteoporosis and osteoarthritis or had any surgery related to bone were excluded from the study.

An Interview schedule was designed to obtain information regarding life style and anthropometric measurements and food frequency questionnaire was also administered. Food frequency questionnaire included foods that are rich in calcium and also those that can affect the calcium metabolism. Intake of calcium supplement was also taken under consideration for the assessment of dietary and supplemental intake of calcium. Question was asked regarding the life style of post-menopausal women such as alcohol intake, smoking, and intake of coffee, intake of tea or use of any sunscreen creams, exposure to sun, exercise or consumption of carbonated beverages. Anthropometry measurements like height, weight and BMI were taken for calculation. According to their BMI subjects were divided into normal weight, over weight and obese.

Table 1: Classification of BMI as per WHO cut offs

\begin{tabular}{|l|c|l|}
\hline Classification & BMI $\mathbf{( k g / \mathbf { m } ^ { 2 } )}$ & \multicolumn{1}{|c|}{ Risk of co-morbidities } \\
\hline Underweight & $<18.5$ & $\begin{array}{l}\text { Low (but increased risk of other } \\
\text { clinical problems) }\end{array}$ \\
\hline Normal range & $18.5-22.9$ & Average \\
\hline Overweight & $\geq 23$ & \\
At Risk & $23-24.9$ & Increased \\
Obese I & $25-29.9$ & Moderate \\
Obese II & $\geq 30$ & Severe \\
\hline
\end{tabular}

The above table is the international classification proposed by World Health Organization (WHO), 2004. ${ }^{8}$

DEXA Scan reports were used for the measurement of bone mineral density of post-menopausal women. BMD of femoral neck left, femoral neck right and lumbar spinal bone were measured at the time of interview. World Health Organization WHO (Nordin et al, 1966) table was used to categorize bone density as: Normal bone: T-score better than or above -1 , Osteopenia: T-score between -1 and -2.5 , Osteoporosis: T-score less than $-2.5 .{ }^{9}$

Data was analyzed using statistical package for social science (SPSS) software, version 21.0. All data were normally distributed and expressed as mean \pm standard deviation. One way analysis of variance (ANOVA) and Pearson chi-test were used for the comparison of variables with $P$ value less than 0.05 was considered significant.

\section{Results}

Fifty postmenopausal women were interviewed for the study. As shown in table no. 2.The mean ages of the women were 53 years. The Mean age of women at their menarche and last menses was 14.6 years and 46.3 years. As per their food habits, $50 \%$ of women were lacto vegetarian, $48 \%$ of women were non-vegetarian and only $2 \%$ of women were vegetarian (vegan). It shows that majority of women were lacto vegetarian. Anthropometric measurement was also taken. As per the measurements the mean of height, weight and BMI of the post-menopausal women was $155 \mathrm{~cm}( \pm 5.220), 53.1$ $\mathrm{kg}( \pm 9.825)$ and $28.3 \mathrm{~kg} / \mathrm{m}^{2}( \pm 4.215)$ respectively.

Table 2: Demographic characteristics of subjects included in the study: $(n=50)$

\begin{tabular}{|l|c|c|c|c|}
\hline $\begin{array}{c}\text { Demographic } \\
\text { characters }\end{array}$ & $\begin{array}{c}\text { Number of } \\
\text { subjects (n) }\end{array}$ & Percent \% & Mean & $\begin{array}{c}\mathbf{\pm} \text { Std. } \\
\text { Deviation }\end{array}$ \\
\hline Total number & 50 & - & - & - \\
\hline Mean age of women & - & - & 53.14 & \pm 4.777 \\
\hline $\begin{array}{l}\text { Mean age at first } \\
\text { menses }\end{array}$ & - & - & 14.16 & \pm 1.283 \\
\hline $\begin{array}{l}\text { Mean age at last } \\
\text { menses }\end{array}$ & - & - & 46.30 & \pm 3.315 \\
\hline Food habits: & 1 & 2.0 & - & - \\
\hline Vegetarian & 25 & 50.0 & - & - \\
\hline Lacto Vegetarian & 24 & 48.0 & - & - \\
\hline Non-Vegetarian & & & & \\
\hline Anthropometry: & - & - & 155.02 & \pm 5.220 \\
\hline Height(cm) & - & - & 67.18 & \pm 9.825 \\
\hline Weight(kg) & - & - & 28.37 & \pm 4.215 \\
\hline BMI(kg/m2)
\end{tabular}


According to the BMI of post-menopausal women, they were divided into categories of underweight, normal weight, at risk of obesity, grade I obesity and grade II obesity. As presented in the Fig. 1. The percentage of women with the category of underweight, normal weight, at risk of obesity, grade I obesity and grade II obesity were $2 \%$, $4 \%, 18 \%, 42 \%$ and $34 \%$ respectively. This shows that majority of the women were in grade 1 and grade 2 obesity category and very few women were having normal body weight.

\section{Fig. 1: Percentage of subjects in various categories of BMI}

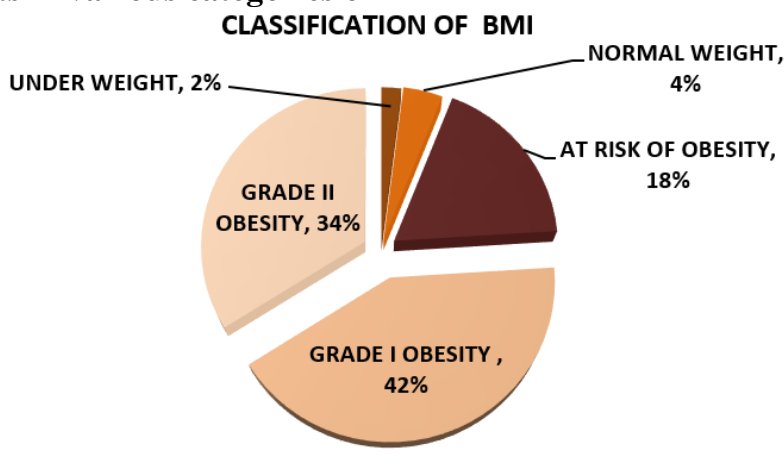

On the basis of the intake of calcium supplement by post-menopausal women about $26 \%$ women were taking calcium supplement regularly and $74 \%$ of women were not taking calcium supplement and this shows that very few post-menopausal women were taking calcium supplement that is shown in Fig. 2.

Fig. 2: Intake of calcium supplement of post-menopausal women

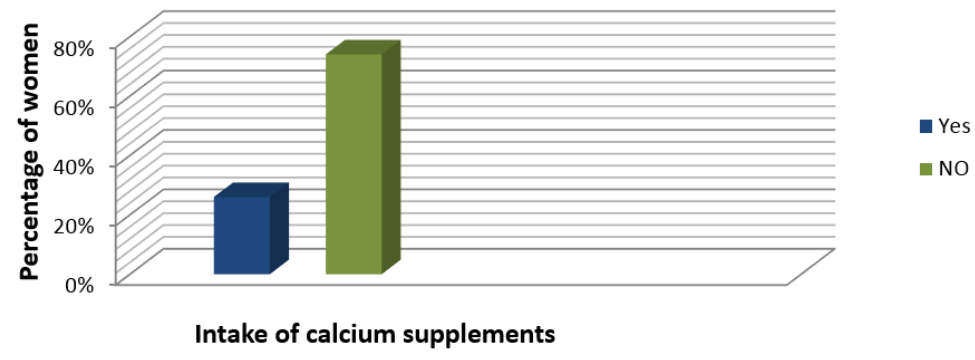

As per the BMD measurement of AP lumbar spine (L1-L2) region, about $41 \%$ of women were with normal BMD, $45 \%$ of women had osteopenia and 14\% women had osteoporosis. According to the BMD measurement of femoral neck left, only $37 \%$ of women were had normal BMD, 53\% of women had osteopenia and $10 \%$ of women had osteoporosis. As per the BMD measurement of femoral neck right $41 \%$ of women were having normal BMD, $51 \%$ of women had osteopenia and 8\% of women had osteoporosis as shown in Fig. 3.

Fig. 3: Bone mineral density of three bone sites of post-menopausal women $(n=50)$

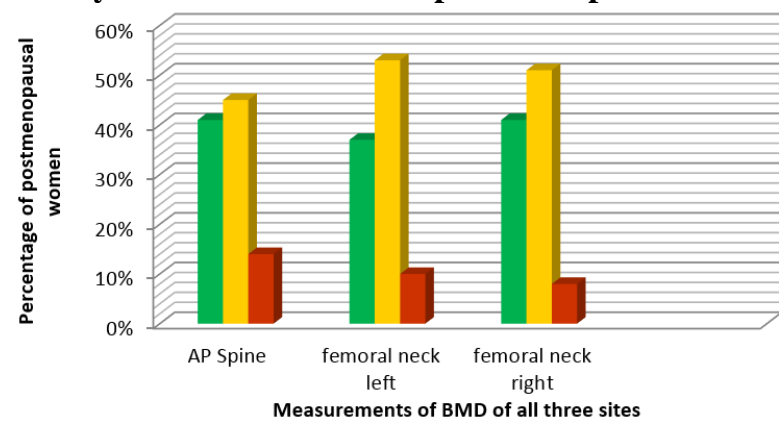

Normal

Osteopenia

- Osteoporosis

Measurements of BMD of all three sites

Percentage of women with normal BMD, osteopenia and osteoporosis by taking the mean of BMD at all the three sites was also measured. It was observed, $39.6 \%$ of women were having normal BMD, $49.6 \%$ of women were having osteopenia and $10.8 \%$ were having osteoporosis. As per the mean BMD measurement of all three sites shows that there was a majority of women were having osteopenia or most of them were at risk of developing fracture and few already had osteoporosis in all three sites of bones that is presented in Fig. 4. 
Fig. 4: The mean percentage of women with normal BMD, osteopenia and osteoporosis of three sites Percentage of women with normal BMD, osteopenia and osteoporosis(by taking mean of BMD at all three sites)

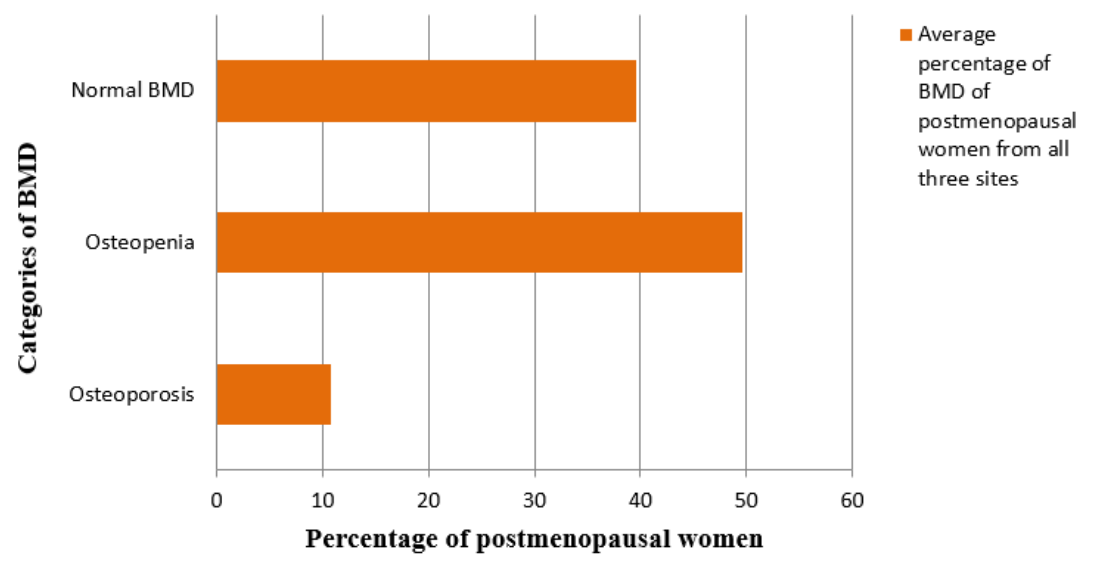

The BMI of post-menopausal women were compared with BMD of three different sites bone that is Ap lumbar spine (L1-L4) region, femoral neck left and femoral neck right. There was a significant difference between the BMI of post-menopausal women with BMD of femoral neck right $(\mathrm{p}=0.045)$ and it was observed, all women were osteoporotic (100\%) in the underweight category. There was no significance difference between the BMI of postmenopausal women with AP lumbar spine and femoral neck left. These results show that BMI have an effect on BMD. Being underweight may have negative effects on BMD of post-menopausal women.

Table 3: Comparison of BMI of post-menopausal women with the BMD measurements of three sites: (p value less than 0.05 is considered significant)

\begin{tabular}{|c|c|c|c|c|}
\hline \multirow{3}{*}{$\begin{array}{c}\text { BMI of post- } \\
\text { menopausal women }\end{array}$} & \multicolumn{3}{|c|}{ BMD measures of all three sites } & p-values \\
\hline & \multicolumn{3}{|c|}{ AP lumbar spine(L1-L2) (\% within BMI) } & \multirow{7}{*}{0.139} \\
\hline & Normal & Osteopenia & Osteoporosis & \\
\hline Under weight & $0.0 \%$ & $0.0 \%$ & $100.0 \%$ & \\
\hline Normal weight & $100.0 \%$ & $0.0 \%$ & $0.0 \%$ & \\
\hline At risk of obesity & $33.3 \%$ & $44.4 \%$ & $22.2 \%$ & \\
\hline Grade I obesity & $47.4 \%$ & $42.1 \%$ & $10.5 \%$ & \\
\hline \multirow{3}{*}{ grade II obesity } & $35.3 \%$ & $58.8 \%$ & $5.9 \%$ & \\
\hline & \multicolumn{3}{|c|}{ Femoral Neck Left (\% within BMI) } & \multirow{7}{*}{0.069} \\
\hline & Normal & Osteopenia & Osteoporosis & \\
\hline Under weight & $0.0 \%$ & $0.0 \%$ & $100.0 \%$ & \\
\hline Normal weight & $0.0 \%$ & $100.0 \%$ & $0.0 \%$ & \\
\hline At risk of obesity & $33.3 \%$ & $66.7 \%$ & $0.0 \%$ & \\
\hline Grade I obesity & $42.1 \%$ & $52.6 \%$ & $5.3 \%$ & \\
\hline \multirow[t]{3}{*}{ grade II obesity } & $41.2 \%$ & $47.1 \%$ & $11.8 \%$ & \\
\hline & \multicolumn{3}{|c|}{ Femoral Neck Right (\% within BMI) } & \multirow{7}{*}{0.045} \\
\hline & Normal & Osteopenia & Osteoporosis & \\
\hline Under weight & $0.0 \%$ & $0.0 \%$ & $100.0 \%$ & \\
\hline Normal weight & $50.0 \%$ & $50.0 \%$ & $0.0 \%$ & \\
\hline At risk of obesity & $44.4 \%$ & $55.6 \%$ & $0.0 \%$ & \\
\hline Grade I obesity & $42.1 \%$ & $52.6 \%$ & $5.3 \%$ & \\
\hline grade II obesity & $41.2 \%$ & $52.9 \%$ & $5.9 \%$ & \\
\hline
\end{tabular}

Frequency of consumption of calcium rich foods were also compared with the BMD measurements of all three sites of bone. There was a significant positive association found between BMD measurements of AP lumbar spine with frequency of intake of green gram dal $(\mathrm{p}=0.041)$, the BMD of femoral neck left was positively associated with the frequency of consumption of ragi or finger millet $(0.056)$, coconut dry $(\mathrm{p}=0.029)$ and gingelly seed $(\mathrm{p}=0.001)$ and 
the BMD of femoral neck right was also positively associated with the frequency of consumption of ragi $(\mathrm{p}=0.009)$, milk (buffalo's) ( $\mathrm{p}=0.058$ ) and milk (cow's) ( $\mathrm{p}=0.045)$ of post-menopausal women as given in Table 4.

So the result of correlation with dietary intake shows that the increase frequency of consumption of calcium rich food is associated with a decrease risk of having low BMD in post-menopausal women. This shows higher intake of calcium rich food may have a positive effect on BMD of post-menopausal women.

Table 4: Correlation of the frequency of calcium rich food intake of post-menopausal women with their BMD measurements: $(n=50)$

\begin{tabular}{|l|c|c|c|}
\hline \multicolumn{1}{|c|}{ Food group } & \multicolumn{3}{|c|}{ BMD measurements (p-values) } \\
\hline & $\begin{array}{c}\text { Ap lumbar spine } \\
\text { (L1-L2) }\end{array}$ & $\begin{array}{c}\text { Femoral neck } \\
\text { left }\end{array}$ & $\begin{array}{c}\text { Femoral neck } \\
\text { right }\end{array}$ \\
\hline Ragi (finger millet) & 0.143 & $0.056^{*}$ & $0.009^{*}$ \\
\hline Red gram dal & 0.159 & 0.643 & 0.472 \\
\hline Green gram dal & $0.041^{*}$ & 0.240 & 0.322 \\
\hline Cauliflower leaves & 0.202 & 0.389 & 0.503 \\
\hline Fenugreek leaves & 0.422 & 0.158 & 0.120 \\
\hline Almonds & 0.564 & 0.117 & 0.738 \\
\hline Coconut dry & 0.703 & $0.029^{*}$ & 0.310 \\
\hline Piyal seeds & 0.216 & 0.762 & 0.556 \\
\hline Gingelly seeds & 0.330 & $0.001^{*}$ & 0.276 \\
\hline Milk (Buffalo's) & 0.182 & 0.209 & $0.058^{*}$ \\
\hline Milk (Cow's) & 0.474 & 0.223 & $0.045^{*}$ \\
\hline Curds & 0.795 & 0.394 & 0.868 \\
\hline Cheese & 0.503 & 0.288 & 0.219 \\
\hline Paneer(Buffalo's) & 0.423 & 0.707 & 0.742 \\
\hline Paneer (cow's) & 0.607 & 0.218 & 0.184 \\
\hline
\end{tabular}

*Difference in the frequency of consumption are considered significant at a $\mathrm{p}$ value $<0.05$

There was no significant association found between the intake of calcium supplement with the BMD of femoral neck right and Ap lumbar spine. There is only a significant association found with the intake of calcium supplement and BMD of femoral neck left $(\mathrm{p}=0.03)$ given in table no.5. As per this comparison, women who were taking calcium supplement there were more number of women with normal BMD $(46.2 \%)$ than women with osteopenia (30.8\%) and women with osteoporotic (23.1\%). In women who were not taking supplement, there is less number of women having normal BMD (34.3\%) and more number of women having osteopenia (62.9\%). This shows there is significant correlation between the calcium supplement intakes with bone mineral density of post-menopausal women.

Table 5: Comparison of the intake of calcium supplement with the bone mineral density of post-menopausal women

\begin{tabular}{|l|c|c|c|}
\hline \multicolumn{1}{|c|}{ BMD measurements } & \multicolumn{2}{|c|}{ Intake of calcium supplements } & p-values \\
\hline Ap lumbar spine & Yes & No & \multirow{2}{*}{0.065} \\
\cline { 1 - 3 } Normal & $30.8 \%$ & $45.7 \%$ & \\
\cline { 1 - 3 } Osteopenia & $38.5 \%$ & $48.6 \%$ & \\
\cline { 1 - 3 } Osteoporosis & $30.8 \%$ & $5.7 \%$ & \\
\cline { 1 - 3 } Femoral neck left & Yes & No & \multirow{2}{*}{0.033} \\
\cline { 1 - 3 } Normal & $46.2 \%$ & $34.3 \%$ & \\
\cline { 1 - 3 } Osteopenia & $30.8 \%$ & $62.9 \%$ & \multirow{2}{*}{0.280} \\
\cline { 1 - 3 } Osteoporosis & $23.1 \%$ & $2.9 \%$ & \\
\cline { 1 - 3 } Femoral neck right & Yes & No & \\
\hline Normal & $38.5 \%$ & $42.9 \%$ & \\
\hline Osteopenia & $46.2 \%$ & $54.3 \%$ & \\
\cline { 1 - 3 } Osteoporosis & $15.4 \%$ & $2.9 \%$ & \\
\hline
\end{tabular}

The comparison was done with few life style habits such as exercise pattern, alcohol consumption, coffee consumption, tea consumption, sun exposure, use of any sunscreen cream, intake of carbonated drinks with measurements of BMD of Ap lumbar spine, femoral neck left and femoral neck right of post-menopausal women. There was a significant correlation found between the BMD of femoral neck left and femoral neck right with the coffee consumption ( $\mathrm{p}=0.007$ and $\mathrm{p}=0.004$ ) of post-menopausal women as given in the Table 6 . 
Table 6: Comparison of life style habits of post-menopausal women with the BMD of Ap lumbar spine (L1-L2), Femoral neck left and Femoral neck right

\begin{tabular}{|l|c|c|c|}
\hline \multicolumn{1}{|c|}{ Life style habits } & $\begin{array}{c}\text { Ap Lumbar } \\
\text { Spine (L1-L2) }\end{array}$ & $\begin{array}{c}\text { Femoral } \\
\text { neck left }\end{array}$ & $\begin{array}{c}\text { Femoral } \\
\text { neck right }\end{array}$ \\
\hline Exercise & 0.264 & 0.186 & 0.758 \\
\hline Alcohol consumption & 0.452 & 0.651 & 0.651 \\
\hline Coffee consumption & 0.083 & 0.007 & 0.004 \\
\hline Tea consumption & 0.457 & 0.721 & 0.565 \\
\hline Sun exposure & 0.748 & 0.602 & 0.228 \\
\hline Use of any sunscreen cream & 0.845 & 0.463 & 0.580 \\
\hline Intake of carbonated drinks & 0.479 & 0.159 & 0.653 \\
\hline
\end{tabular}

Difference is Significant at $\mathrm{p}$ value less than 0.05

According to this comparison, based on the BMD of femoral neck left and femoral right, about $78 \%$ of women who consume coffee had osteopenia or were at risk of osteoporosis in both the site. This shows that consumption of coffee can have a negative effect on BMD of femoral neck left and femoral neck right of post-menopausal women and the differences were significant with a $p$ value $<0.05$

Table 7: Comparison of the percentage of post-menopausal women in various categories of BMD of the bone sites femoral neck left and femoral neck right with coffee consumption pattern

\begin{tabular}{|c|c|c|c|}
\hline BMD sites & Coffee c & mption & $P$ - value \\
\hline Femoral neck left & Yes & No & \multirow{4}{*}{$0.007 *$} \\
\hline Normal BMD & $10.5 \%$ & $55.6 \%$ & \\
\hline Osteopenia & $78.9 \%$ & $37.0 \%$ & \\
\hline Osteoporosis & $10.5 \%$ & $7.4 \%$ & \\
\hline Femoral neck right & Yes & No & \multirow{4}{*}{$0.004 *$} \\
\hline Normal BMD & $10.5 \%$ & $59.3 \%$ & \\
\hline Osteopenia & $78.9 \%$ & 53.3 & \\
\hline Osteoporosis & $10.5 \%$ & $3.7 \%$ & \\
\hline
\end{tabular}

*Difference in the consumption of coffee in the BMD categories are considered significant at a p value $<0.05$

\section{Discussion}

A total of 50 postmenopausal women were interviewed for the study. Data was collected on bone mineral density of postmenopausal women, anthropometry, their life style, dietary intake and physical activity for the study. The age group of women was 40 - 60 years, as there is more prevalence of low BMD in this age group of women. Which is supported by the study Damodar et al, 2000 that incidence of osteoporosis occurs in at the age of 50-60 years. ${ }^{10}$ According to the study by Maj et al, 2012 the prevalence of osteoporosis and osteopenia was $13.3 \%$ and $48.1 \%$, which was studied on 158 women. Nearly similar result was found in the present study, the prevalence of osteoporosis and osteopenia was $10.8 \%$ and $49.6 \%$ respectively. ${ }^{11}$

The importance of body weight in determining both bone mass $\&$ fracture risk has been emphasized by the National osteoporosis foundation. In the present study, there was a significant association found between BMI and BMD of post-menopausal women $(\mathrm{p}=0.004)$. There was negative association found between the degree of underweight and BMD of post-menopausal women, which is also supported by many studies. There was also a study done on BMI as predictor of bone mineral density in postmenopausal women in India, which stated that low weight and BMI predict osteoporosis and are associated with increased risks in postmenopausal women. The negative impact of low body weight on bone health should be more widely recognized (Helena et al, 2014). ${ }^{12}$ Same result was also found by Farzaneh et al 2014, indicated that older women with low BMI were at higher risk of low bone mass. ${ }^{13}$

The effect of calcium supplementation on BMD has been demonstrated in this group of young adult women. These results showed the positive effect of calcium supplementation in women both peri and postmenopausal status; for this reason a supplementation of calcium should be recommended as a strategic option in helping to prevent early postmenopausal bone loss (Nicola et al, May 2004). ${ }^{14}$ Also in the present study, there was a significant association found with intake of calcium supplement and BMD of femoral neck left of postmenopausal women and this shows that calcium supplemental intake may have positive protective effects on BMD of postmenopausal women. This is also supported by another study that concluded a lower calcium dietary intake in postmenopausal women, increases osteoporosis (Esra et al, 2013). ${ }^{15}$

Nutrition, lifestyle, and genetics may all contribute to the decrease in BMD that comes with aging and leads to osteoporosis, a major cause of fractures in the elderly. Previous research implicated caffeine increased risk for hip fracture and poor calcium retention (Oct, 2001, 
American Journal of Clinical Nutrition)..$^{16}$ In this study, a significant negative association was found between the coffee consumption and BMD of femoral neck right and femoral neck left $(\mathrm{p}=0.004$ and $\mathrm{p}=0.007$ ) of postmenopausal women. Women with positive coffee consumption were having osteopenia. This shows coffee consumption may have negative effects on BMD of postmenopausal women. Supported by Kristin et al, 2003, which also concluded that caffeine consumption may have a weak negative influence on BMD of postmenopausal women. ${ }^{17}$ Study by Hellstrom et al, 2013 also showed high coffee consumption was associated with a small reduction in bone density that did not translate into an increased risk of fracture. ${ }^{18}$

\section{Conclusion}

As per the result, it is concluded that intake of calcium rich food, calcium and vitamin D supplements can have a positive effect on bone mineral density of post-menopausal women. On the other hand lower BMI and coffee intake may have negative effects on bone mineral density of post-menopausal women. This study shows that dietary intake and life style patterns of postmenopausal women may have negative and positive effect on bone mineral density.

\section{References}

1. Schwartz AV, Selimeyer DE, Ensrud KE, Cauley JA, Tabor HK, Schreiner PJ et al," Older women with diabetes have an increased risk of fracture a prospective study." J Clin Endocrinol Metab 2001;86(1):32-8.

2. Finkelstein J S, et al .J clin Endocrinol Metab 2008," Bone mineral density changes during the menopause transition in a multiethnic cohort of women."

3. Delmas PD, Fraser M. Strong bones in later life: luxury or necessity? Bull World Health Organ 1999;77(5):416-22.

4. Mithal A, Nangia S, Arya V, Verma BR, Gujral RB. Spinal bone mineral density in normal Indian females. $J$ Bone Miner Res 1998;13(Suppl 1):S591.

5. Gupta Ak, Samuel KC, Kurian PM, RallenRc. Preliminary study of the incidence \&aetiology of femoral neck fracture in Indians. Indian J Med Res 1967;55:1341 - 8.

6. Akbar Soltani1, Bagher Larijani1, Patricia Khashayar, Mohsen Rezaei Hemami2, and Sima Fakhari, The Relationship between Anthropometric Parameters and Bone Mineral Density in an Iranian Referral Population (12 July 2013).
7. Tandon N, Marwaha RK, Kalra S, Gupta N, Dudha A, Kochupillai N. Bone mineral parameters in healthy young Indian adults with optimal vitamin D availability. Natl Med J India 2003;16:298-302.

8. World Health Organization (WHO), 2004.

9. Nordin BEC. International patterns of osteoporosis. Clin Orthop 1966;45:17-30.

10. Damodaran P, Subramaniam R, Omar SZ, Nadkarni P, Paramsothy M., Singapore Med J 2000;41(9):431-5, "Profile of a menopause clinic in an urban population in Malaysia"

11. Cross sectional study of osteoporosis among women Tripti Agrawal, Maj ${ }^{\mathrm{a}, *}$ and A.K. Verma, Brig Med J Armed Forces India 2012;69(2):168-71.

12. A Meta-Analysis of the Association of Fracture Risk and Body Mass Index in Women. Helena Johansson John A Kanis, Anders Odén, Eugene McCloskey, Roland D Chapurlat, Claus Christiansen, Steve R Cummings, Adolfo Diez-Perez, John A Eisman June 2014 jbmr

13. Farzaneh Montazerifar 1; Mansour Karajibani 2; Sara Alamian 3; MahnazSandoughi 4; Zahra Zakeri 2,4; Ali Reza Dashipour "Age, Weight and Body Mass Index Effect on Bone Mineral Density in Postmenopausal Women" Health Scope. 2014;3(2):e14075.

14. Nicola Di Daniele, Maria Grazia Carbonelli, Nicola Candeloro, Leonardo Iacopino, Antonino De Lorenzo*, Angela Andreoli. "Effect of supplementation of calcium and Vitamin D on bone mineral density and bone mineral content in peri- and post-menopause women A double-blind, randomized, controlled trial,". Pharmacol Res 2004;50:63741.

15. Esra Tajik, Yoke Mun Chan, Zalilah Mohd Shariff, Fatemeh Ebrahimi. "Dietary calcium intake and socioeconomic status are associated with bone mineral density in postmenopausal women". World Applied Sci J January 2014.

16. J.A. Mc LEAN, S.I. Bars \& J.C. Prior. Cognitive dietary restraint is associated with higher urinary cortisal excretion in healthy premenopausal women, Am J Clin Nutr 2001;73:7-12.

17. Kristin Holvik1 and Haakon E. Meyer. "The association between caffeine intake and forearm bone mineral density in postmenopausal women: The Oslo Health Study". Norsk Epidemiologi 2003;13(1):177-83.

18. Hallström H, Byberg L, Glynn A, Lemming EW, Wolk A, Michälsson K. "Long-term coffee consumption in relation to fracture risk and bone mineral density in women". Am J Epidemiol 2013;178(6):898-909.

19. Karause's Food \& Nutrition therapy; (L. Kathlce Mohan Sylvia, Escott - stamp) 12 edition.

20. Susan A. New and Jea - Philippe Bojour, Nutritional aspects of Bone health 2003. 